\title{
Production of high yield sugars from Kappaphycus alvarezii using combined methods of chemical and enzymatic hydrolysis
}

\begin{abstract}
The characteristics and functional properties of polysaccharides extracted from Malaysia's seaweeds have not been fully established to date. Hence, this study was carried out to produce high yield fermentable sugars from Kappaphycus alvarezii for the potential production of biotechnology products such as bioflavours. In order to achieve this objective, the effectiveness of hydrolysis process was studied by using chemical treatments, followed by enzymatic treatments. K. alvarezii were hydrolysed in different heating times and temperatures followed by different types of acids and their concentrations. The optimal conditions for chemical hydrolysis were achieved at $8.0 \mathrm{~g} / 100 \mathrm{~mL}$ of dried powder $\mathrm{K}$. alvarezii in $0.2 \mathrm{M} \mathrm{H} 2 \mathrm{SO} 4$ and $\mathrm{HCl}$ at $110{ }^{\circ} \mathrm{C}$ for 90 min which produced $34.275 \pm 0.976 \mathrm{~g} / \mathrm{L}$ and $35.872 \pm 3.610 \mathrm{~g} / \mathrm{L}$, respectively with $42.8 \%$ and $44.8 \%$ of yield of sugar production. However, there are no significant different between $\mathrm{H} 2 \mathrm{SO} 4$ and $\mathrm{HCl}$. Thus, $\mathrm{H} 2 \mathrm{SO} 4$ was chose as a catalyst for chemical hydrolysis. As for the combination of chemical and enzymatic hydrolysis, several $\mathrm{pH}$ of hydrolysates and incubation temperature were studied. The optimum condition for Celluclast activity was at $\mathrm{pH} 5.5$ and $50{ }^{\circ} \mathrm{C}$ incubation temperature which produced the highest reducing sugars with an increment of $15.60 \mathrm{~g} / \mathrm{L}$ from the chemical hydrolysis alone. The yield of reducing sugars after combining both methods reached $62.35 \%(49.92 \pm 1.163 \mathrm{~g} / \mathrm{L}$ reducing sugar). From this study, the characterization of these seaweeds can lead to a better understanding of their functional characteristics and promote the exploitation of these natural resources for the production of expensive new biotechnology products.
\end{abstract}

Keyword: Reducing sugars; Seaweeds; Chemical hydrolysis; Enzymatic hydrolysis 